\title{
Culture and Built-form in the Making; An examination of the Asian and Sri Lankan Urban Space
}

\author{
Ranjith Dayaratne
}

\begin{abstract}
The dawn of the new millenium is characterized by the fast and abrupt change in cultures across the world, propelled largely by western thoughts, ideas and practices. Asia is no exception and has been in the forefront of this change in terms of economy, social patterns and indeed the built-form. 1980s saw a vibrant economic growth in Asia, followed by social, cultural and environmental transformations hitherto unknown in the Asian history, that some of those economies were even dubbed "tiger economies". Despite the collapses of those economies and turmoil that prevailed at the end of the last millenium, the social and environmental transformations have not seen any conceptual set-back but a steady progression towards a universal uniformity coloured only thinly by a subtle diversity of cultural grain.
\end{abstract}

This paper examines the nature of the efmerging Asian urban space and the way in which its spatiality is generated. nurtured and transformed in a people-driven highly politicized cultural process.

\section{Asian Culture: A Search for Definitions}

If one were to classify the cultures across the world into some kind of sectors, it may be possible to talk largely about American, European, Middle-Eastern, African and Asian cultures, and almost all cultures could be positioned within one of these geographically identified domains. Regional anchorage seem to be the way in which we perceive the global cultural variations and affinities which indeed suggest a co-relation between the geography of the regions and the characteristics of the societies naturally inhabiting them.

Although these terms seem to refer to particular geographical regions in the world, it is also possible to locate cultures geographically present in regions not belonging to these categories. For example, Australia and Newzealand have European cultures while they exist at the south-most end of Asia. Nevertheless, apart from such exceptions, affinity of a culture to a geographic region is a strong one. Asia, though not a small territory to possess a uniform culture across its vast region could be seen to possess some unifying characteristics that could identify them as belonging to what we may call an Asian Culture. The similarities within diversity of Asian Cultures is well-acknowledged in the formation of institutions cultural as well as social or economic and seem to provide its people a basis for unification, shared understanding and indeed feelings of brotherhood despite strikingly different cultural orientations.

Indeed, the geographic region of Asia is not synonymous with Asian Cultures. Diverse cultures exist of which only some could be called distinctly Asian while others can not be. However, the elements that make them up seem similar for reasons of history, geography, religion and sometimes worldviews. Benedict offers us the configurational interpretation of cultures that help understand these diversities. According to Benedict, (1968) the configuration of culture or the genius of the culture is dependent upon elements and traits, the integration of which in a particular form defines a specific culture. Thus cultures may differ on the whole while having similar elements and traits that make them up. As Hoebel (199) puts it, the bricks that go to make a fire-place, a cess-pool or a garden wall are similar. But the arrangement and the interaction of bricks in each of them are different and as a result, the constructed entities differ in shape and function.

Benedict, (1968) points out that there are two distinct cultural groups in the world; those which could be termed either as Appolonian or Dynosian cultures. The characteristics of appolonian cultures are such that they stress restraint and orderliness in behaviour, avoidance of emotional excess and display in personal experience and ritual and a rigorous suppression of individual initiative and innovation with quiet co-operation in group endeavor. Those who are under the influence of Appolonian cultures emphasize the middle path; a way of life that avoids extremes of sense-behaviour. Appolonian cultures tend to distrust and suppress individualism as a disruptive unbalancing force. Economic wealth is of little cultural interest, food although important, hardly bring about any obsession based purely on their economic values.

In contrast, the Dynosian cultures emphasize a break away from usual sensory routine, and seek vision by extreme forms of torture of both mind and body. They 
seek to achieve an order of experience set apart from daily living, while vision-experience is sought openly by means of drugs and alcohol. Violent experiences are valued, marriage and death are considered elaborate rituals for indulgence in extravagance.

However, this is not to suggest that there are only two categories of cultures in the world. In fact, there are subtle variations of this bi-polarity, but it is quite clear that the dynosian and appolonian traits indicate the two extreme ends of this bi-polarity. At the same time, there may be cultures that display the characteristics of both these extremities fused in specific ways to make up one of their own.

Viewed this way, traditional Asian cultures can be seen to have had both Appolonian, and Dynosian cultures, existing totally separately and sometimes fused with each other. For example, as Wickramsinghe (1992) points out, Hindu culture is Dynosian with a mixture of appolonian elements. On the contrary, Buddhist cultures are Appolonian with little dynosian inclinations. Islamic cultures on the other hand are a mix of Appolonian and Dynosian cultures. Interestingly, the cultural variations in Asia are religion-bound more than other aspects and the centrality of religion in culture is a significant one. Religion offers the Asian people ways of life, the world-views and indeed a point of anchorage and linkages in the social structure. It is in the midst of these cultural variations, that the urban spaces are located and the case of Urbanity in Asia poses yet another complexity particularly because in Asia, the duality of urbanity and ruralness are equally fused.

\section{Urban Rural Dichotomy and Urbanity in Asia}

The urban rural dichotomy in Asia is an interesting one. The first question that we come to face in understanding this is whether urban rural duality is a social one or a spatial one. Most often, it is interpreted as a characteristic of the societies and communities, while planning literature depend heavily on spatial characteristics to define urbanity. From a social point of view, urban means societies that are predominantly industrialized and depend on systems for linkages among people (Walmsey, 1992 ), rather than concentrated high density spaces. However, some argue (Prematilake, 1999) that urbanity means collectivity and that the beginnings of urbanity can be traced down to the center of the village square; a spatial gesture of coming together for communal living, trade and enterprise. If we accept this argument, we may conclude that the best form of urbanity existed in the most primitive tribal settlements rather than in the contemporary metropolis, and urbanisation then will mean something entirely different from what is taking place today. Since in the former the sense of collectivity is at its best, whereas in the contemporary settlement, communities live in congestion but as separately as possible. This paper takes the view that urbanity is primarily a social condition and that we can understand, interpret and deal with urbanity in a socially relevant manner, only if we accept that this social condition is not necessarily attached to any spatial characteristic. Thus we may talk of urban societies, urban cultures and urban people, whose places of habitation could be recognized as urban spaces, rather than the vice versa.

In this sense, the traditional Asia is to be considered primarily rural, although there is now an emerging urbanity in some capitals and concentrated settlements of few Asian countries. If urbanity were to mean highly populated dense settlement spaces where the built-tounbuilt ratio is high, then again Asian settlements are largely rural. There is no dispute that Asian settlements are particularly small, scattered ones and are not concentrated high-density spaces.

At the same time, if we look at urbanity versus ruralness as a way of living and how a society is organized and interrelated, then most Asian communities are socially heavily linked and interdependent, a characteristic we may distinguish as rural. From a social point of view, urban societies are those which have less social linkages but mechanistic procedural, administrative and technical linkages which make up a system that dominates the social presence.

Indeed, this dichotomy manifests in the Asian society and space in distinct and determinant ways that define and locate their culture and built-form. For instance, the so-called urban settlements in Asia are socially not different from rural settlements, except that a larger percentage of people may be making a meager living from services or commerce rather than agriculture. Informal, non-industrialized activities predominate, both in numeric terms and in spatial existence. There is more informality than formality, chaos than order, lack of system than system. Indeed, there is a tremendous difficulty and dislike to bringing in "order and systems" above human factors. I would argue and many others have also suggested, that Asian settlements are largely "Urban Villages", a dichotomous existence of social and spatial characteristics that are contradictory and conflicting with each other.

To illustrate this point, we may take the transport space in the Asian settlement. Even in the so-called cities, and urban spaces, it is not uncommon in many parts of 
Asia to find animals and people alike. People and vehicles of all sorts from the modern cars to bullock carts compete with each other while existing in the same transport space. In most Asian urban spaces, specificity is hard to come-by and almost impossible to maintain. Almost always, there are pedestrians in the vehicular roads, and vehicles in the pavements or pedestrian walkways. Regulations and rules cannot exist above person, and they may be fashioned to suit the individuals at implementation. Most often than not, rules in the shape of the western urban control exist in theory, but will hardly make sense or relate to the realities on the ground. Interestingly, there is an everincreasing conflict between the rulers' and professionals' way of looking at this space and the society actually inhabiting it in the real world.

\section{Asian Built-form}

The Asian built-forms have always been located in the rural space dominated by traditions and conventions immersed in beliefs fashioned by religions. Sharp divisions existed in the way in which the sacred and the profane worlds were conceived and indeed constructed. Notably, the Asian built forms were conceived and refined largely in the area of sacred buildings and settings while the profane buildings and settings remained relatively in-articulated and ignored. Thus the domestic built-forms are of little significance in Asia compared with the sacred, the community and ritualistic places. The sharp division of treatment and conception of the built-forms in these two domains are characterized by the dualities of permanence and impermanence, simplicity and granduer, and excess and poverty associated with them.

\section{Traditional Asian Urban Space:}

Traditionally, Asia could be said not to have possessed either an urban space or an urban community. If urbanity were to mean life and space that is powered and managed by systems rather than social linkages, then one could almost conclude that Asia was entirely a non-urban one. Even the Asian cities that claim histories of thousands of years before the dawn of the European civilisations have not had either an urban space or an urban community that depended and generated social and spatial characteristics from industry and systems. But then we also talk of medieval cities such as the Anuradhapura and Polonnaruwa in Sri Lanka or the Saranath in India or the Boro-Budur in Indonesia.

City in this sense meant that it was the place where a community lived in close proximity in built environments that dominated the natural environment and that their main activities of livelihood were either commerce or administration; in other words there lived the rulers. As opposed to these cities, existed the village; that sharply contrasted with the city both physically and socially. The natural environment outdid the built and the people engaged in agriculture and domestic production for a livelihood; in other words there lived the ruled. It is only if we use the term urban to mean a dense built-environment that we may talk of "urban spaces" that existed in those cities, despite the fact that the essential characteristic of "industry-base or the system-control" in the present definition of urbanity is almost absent in these spaces. Nevertheless, the city spaces in the ancient Anuradhapura or Polonnnaruwa in Sri Lanka were not even dense built-environments controlled by systems and machines, but people.

\section{The New Asian Urban Settlement Space}

The Asian urban settlement space is thus a recent construction, planted firstly by the colonial masters and occupied and consolidated by the local elite. It is the international trade and the subsequent industry associated with colonization that has provided the impetus for the growth of the urban settlement in Asia. For this very reason, it comprises the dualities of the rich and the poor, the formal and the informal, and indeed order as mush as the disorder, that has continued to divide and separate the emerging Asian Urban settlement space.

Shunsuke (1988) identifies these characteristics as follows.

Asian Vs

non- Asian

Mixed land use Vs

Land Use division

Multi- Centre System Vs

Single Centre System

Functional Diversity Vs

Functional division

Invisibility of Centrality Vs

Exposure of Centrality

Short time cycle Vs

Long time cycle

Unprogrammed linkages

of involvement $V s$

Planned Linkages of functions

Participation in common space Vs Protection of privacy

Low-rise high density Vs

High rise low-density

Informality and casualness Vs Formality and 
Disorder and seeming chaos Vs

Order

Spontaniety and variety Vs

Planning and Uniformity

The new urbanity of Asia is in fact a transformation of these spatial characteristics from one end of the spectrum to the other in different complexities in parallel with a transformation of appolonian cultures to dynosian ones. On the face of it, they display the characteristics of the American and European cultural grain both social and spatial but deep down lie the processes and concepts that are in conflict and in confusion. Most significantly, both Asian culture and built space are in transition from Asian characteristics to non-Asian ones, while both exist within either a single space or in close proximity to each other.

What this means is that in the emerging cultures and built spaces in Asia, the dualities and dichotomies are consistently present creating not only contradictions but tensions. In other words, the spatial and cultural worlds in Asia are divided and this division and sectorial hegemonies propagate reciprocal processes in both domains that continue to erode the social and spatial cohesion that existed in the traditional cultures and traditional built-forms.

The concepts and models, that come in to being in this process are numerous, but can be classified as being predominantly of three-forms. On the one hand, there is the emerging new Asian built space and culture, refined and reformed to the level almost of European likeness in concepts and detail, and on the other, there is the traditional conventional built-space and culture which claim authenticity and demand faithful subordination. At the same time, there is also the one in transition, in tension, and in confusion of conceptual, perceptual and functional contradictions. We may call them the Euro-asian model (EA), the ConventionalAsian model (CA) and the Trnasitionary Asian model (TA). The three are not mutually exclusive of each other but exist and exact the essence of daily life in the Asian societies.

However, the degree of their presence in one or another of the urban locations or countries differ and it is to this extent that the Asian Urban Places can be said to have undergone urbanization or otherwise. To be more specific, the more economically developed countries in Asia, such as Japan, Singapore, South Korea and Malaysia; those dubbed the "tiger economies" could be said to possess more of the urban spaces and cultures akin to the EA model, and the rest in the TA model while there may be few spaces of the CA model.
In contrast, there are the moderately economically developed countries possessing more of the TA, and equal or more of the $\mathrm{CA}$ while few of the $\mathrm{EA}$ model. There are in fact a number of scenarios of these mixes but essentially three specific formations that could be illustrated as follows.

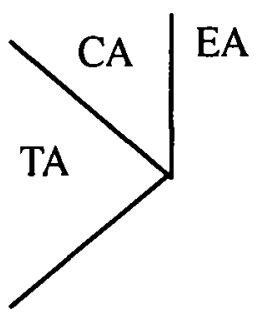

In this situation, most urban spaces of a country have undergone the transformation from the conventional form to the Euro-Asian form, most other spaces are in Iransition and a small portion remains in conventional form.

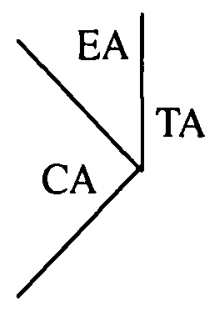

In this situation, only a small percentage of urban spaces have undergone the transformation to Euro-Asian form while most urban spaces are in the process of transition from the Conventional Asian form to the Euro Asian form. A large portion also remain in the Conventional Asian form

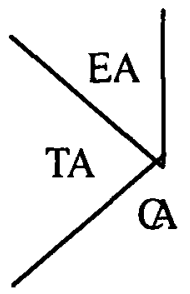

In this situation, most of the urban spaces remain in the Conventional Asian form while a larger portion of the built environment is in transition from the conventional to the Euro-Asian form. Only a small portion of the urban spaces have become fully transformed into the European Asian Model

\section{Asian culture and built-form in the new millenium Characteristics emerging:}

It is clear from this analysis, that the emerging urban spaces, and cultures driving them and the built-forms defining and giving expression to them offer similar experiential encounters despite the degrees of variety 
in the way in which the element and traits are fused together. In essence they are all moving in a singular direction; ie towards the European culture and European spatial conceptions and models. Nevertheless, the emerging spatial and cultural entities cannot deny the existence and their inevitable immersion in the traditional Asian values and affinities that colour them and therefore act as both the anchorage and unification of these cultures.

This then is the constitution of the culture, the builtform and urban space in Asia. However, the significance of the Asian built-forms are also shifting from the sacred to the profane and from the community orientation to the individual celebration. Propelled by the "open economies" that emphasize the individual achievement and gain opposed to the collective enhancement and well-being, the "tiger-economies" take the lead in tying up the Asian transformations to a European led trajectory that is not only unseen but unpredictable.

Interestingly however, the hold of religion in Asian societies is not likely to be outdone in this process, nor will it transfer the social and individual linkages and powers to the systems. Urban monasteries, temples churches and mosques that were not known in the traditional conventional urban Asian space have emerged to re-establish the dominance of religion in the urban landscape despite seeming inability to do so effectively. At the same time, the feudal power is being transferred to the political elite and the economically rich whose authority and presence in this process is unchallenged. In other words, the concepts and processes that propel urbanization and spatial transformation is deeply resident in a culture that is made characteristically dominated by the power and social presence of religion and individuality rather than ideology and reason.

In this context, the dawn of this millenium will pose three potential predominant urban scenarios in Asia; the scenarios prevailing and emerging as discussed in the three situations earlier in this paper. In any of these situations, the Asian urban space is bound to contrive of concomitant dualities that are synonymous

with the Asian characteristics both spatial and social. They will essentially include modernity and tradition, order and chaos, and clarity and confusion, among other things. In othet words, meanings and contradictions of those meanings themselves.

This however also means that the emerging urban space will manifest in place and placelessness; place due distinctiveness of the new and alien artifacts in a humane geography, and placelessness due confusion and chaos. Uncertainty will abound with the casual use of this space in uncaring wilderness of habit and thought.

In this sense, it is not unfair to suggest that the emerging Asian urban space is a potpourri of complex elements and traits diverse in themselves but unifying into a whole of a model of culture and space that is visibly European but fashioned by traditions, conventions and world views deeply resident in religion. A return to the future.

\section{References:}

Dayaratne, R (1999) Urban Rural Dichotomy and Atlachment to Place in Sri Lanka in Architexts, Colombo: Vishvaleka

Iwasaki, Shunsuke (1988) The Physical and Socio-Cultural Features of Settlements and Communities in Asia and Pacific-Towards better appreciation of Indigenous Urban Space in Second Congress of Local Authorities for Development of Human Settlements in Asia and the pacific.

Perera, N (1992) Society and Space: Colonisation and Identity in Sri Lanka

Wickramasinghe, M (1992) Aspects of Sinhalese Culture, Dehiwala, Thisara Prakashakayo

Walmsey D.J. (1992) Urbon Living : The individual in the city Essex : Longman Scientific ans Tecgnical Servies

Prematilake M. (1999) Discussion at staff room univasity \& Moratuwa 